\title{
Lugares de Quintana
}

Marcelo Coelho

Folha de São Paulo

... esse eterno desentendido entre

Espaço e Tempo. ${ }^{1}$

Tudo que brilha vê. ${ }^{2}$

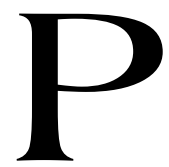

ara qualquer morador de São Paulo, a cidade parece de algum modo infinita. Não há como chegar a seu último subúrbio, como conhecer a sua derradeira rua. Um dos encantos da poesia de Mário Quintana, ao menos para quem lê seus versos de uma ótica "paulista", está na freqüência com que encontramos lugares em que a cidade confina com a noite, com o nada, com a escuridão. Na "Rua dos Cataventos", surge pela primeira vez na obra do poeta uma paisagem desse tipo:

Lá onde a luz do último lampião

Uns tristes charcos alumia embalde,

Moram, numa infinita solidão,

As estrelinhas quietas do arrabalde... ${ }^{3}$

Neste artigo, pretendo situar a poesia de Mário Quintana - que tantas vezes transitou do verso à prosa, do erudito ao popular - dentro da tradição da poesia urbana brasileira, destacando o que poderíamos chamar de sua "geografia íntima", feita de ruazinhas, corredores, esquinas, poços e porões. Gaúcho nascido perto da fronteira, habitante de uma Porto Alegre ainda provinciana, o poeta reflete, quem sabe, a sua própria

\footnotetext{
${ }^{1}$ QUINTANA, 2005, p. 584.

${ }^{2}$ BACHELARD, 1978, p. 219.

${ }^{3}$ QUINTANA, 2005, p. 120.
} 
posição marginal, extravagante, no cânone do modernismo brasileiro. Para fins de comparação, aproximamos a sua obra da de outros poetas, como Mário de Andrade e Carlos Drummond, cuja relação com a cidade se origina de vivências bem distintas.

"Você já leu Verhaeren?" perguntava Mário de Andrade no seu "Prefácio Interessantíssimo" à Paulicéia Desvairada ${ }^{4} \mathrm{O}$ modernista paulistano tomava o livro Cidades Tentaculares, ${ }^{5}$ publicado em 1895 pelo belga Émile Verhaeren (1855-1916), como uma das fontes de inspiração para a poesia da vida urbana, tumultuária e múltipla, que se criava no Brasil dos anos 20.

Os versos que celebravam a "Costureirinha de São Paulo,/ Ítalo-francoluso-brasílico-saxônica", ${ }^{6}$ e meditavam sobre o bairro de Higienópolis, lugar das "Babilônias dos meus desejos baixos", 7 remetiam certamente a algumas passagens de Les Villes Tentaculaires:
Ô les Babels enfin réalisées!
Et cent peuples fondus dans la cité commune;
Et les langues se dissolvant en une:
Et la ville comme une main, les doigts ouverts, Se refermant sur l'univers! ${ }^{8}$

Longe de constituir uma celebração das grandes cidades, a obra de Verhaeren recua horrorizada diante da civilização industrial. Com seus tentáculos, a urbe avança sobre as pacíficas planuras de trigo: "O campo, triste, morre - e a cidade o devora", constata o primeiro poema de Cidades Tentaculares, e é do ponto de vista de uma vida rural perdida que se erigem os sonhos igualitários, hugoanos e progressistas do poeta, cujos versos todavia adotam, na maior parte do tempo, um tom elegíaco:

\footnotetext{
${ }^{4}$ ANDRADE, 1993, p. 61

${ }^{5}$ VERHAEREN, 1999.

${ }^{6}$ ANDRADE, 1993, p. 98.

${ }^{7}$ ANDRADE, 1993, p. 99.

8 "Oh! As Babéis enfim realizadas!/E cem povos fundidos na urbe comum;/E as línguas todas se juntando em uma; E a cidade como uma mão, dedos abertos/ Fechando-se sobre o universo." VERHAEREN, 1999, p. 46 e 47.
} 
Formidables et criminels,

Les bras des machines diaboliques

Fauchant les blés évangéliques,

Ont effrayé le vieux semeur mélancolique

Dont le geste semblait d'accord avec le ciel. ${ }^{9}$

Na visão de Verhaeren, a cidade é ainda um monstro, cuja expansão é ameaçadora; o poeta encolhe-se de horror, tenta proteger-se de seus tentáculos, e embora a conheça de perto, vive "mais além", num lugar ideal, em comunhão com o porvir:

Le futur éclatant est un oiseau de feu,

Dont les plumes, une par une,

Se détachant de l'aile et retombant vers nous,

Frôlent de joie et de splendeur nos regards fous. ${ }^{10}$

No mesmo espírito, mas sem tanta confiança, o poema final de Les Villes Tentaculaires indaga:

Renaîtront-ils, les champs, un jour, exorcisés

De leurs erreurs, de leurs affres, de leur folie;

Jardins pour les efforts et les labours lassés,

Coupes de clarté vierge et de santé remplies?

Referont-ils, avec l'ancien bon soleil,

Avec le vent, la pluie et les bêtes serviles,

En des heures de sursaut libre et de réveil,

Un monde enfin sauvé de l'emprise des villes? ${ }^{11}$

9 "Formidáveis e criminosos,/A máquina e seus braços diabólicos,/Ceifando os trigos evangélicos, /Vêm assustando o bom semeador melancólico/Cujos gestos os céus recebiam ditosos". VERHAEREN, 1999, p. 10-11.

10 "O futuro brilhante é um pássaro de fogo/Cujas penas, uma por uma/Da asa se destacando e caindo até nós,/Roçam com graça e esplendor nosso olhar louco." VERHAEREN, 1999, p. 132-133.

11 "Renascerão, um dia, os campos enfim salvos/De tanto horror, de tantos erros, da loucura;/Jardins para o esforço e o ímpeto cansados,/Taças de claridade e saúde cheias?//Renovarão, com o mesmo sol antigo e bom,/E mais o vento, e a chuva, e os animais servis,/Em horas livres de temor e sobressaltos, Um mundo salvo enfim do domínio das urbes?" VERHAEREN, 1999, p. 140-141. 
Com alguma ironia, mas não muita, essa esperança é retomada por Mário de Andrade nos versos que atribui à "Minha Loucura", fechando o "oratório profano" intitulado "As Enfibraturas do Ipiranga", último poema de Paulicéia Desvairada:

Mas em vinte anos se abrirão as searas!

Virão os setembros das floradas virginais!

Virão os dezembros do Sol pojando os grânulos!

Virão os fevereiros do café-cereja!

Virão os marços das maturações!

Virão os abris dos preparativos festivais!

E nos vinte anos se abrirão as searas!

E virão os maios! E virão os maios! ${ }^{12}$

Mas, no fundo, o movimento esboçado por Mário de Andrade inverte a construção de Verhaeren. Enquanto este se refugia no ideal, afastando-se da cidade, o poeta brasileiro afasta-se do ideal, sabe-se votado a outro destino do que aquele, radioso, que seus versos prenunciavam às "juvenilidades auriverdes". Voltando-se para si mesmo, encontra uma paisagem inóspita e desolada: "Eu... os desertos... os Cains... a maldição..."

É que, ao contrário de Verhaeren, Mário de Andrade já se vê imerso na cidade grande:

Há navios de vela para meus naufrágios!

E os cantares da uiara na rua de São Bento...

Entre estas duas ondas plúmbeas de casas plúmbeas, As minhas delícias das asfixias da alma! ${ }^{13}$

Cidade e poeta se fundem numa coisa só, como indica o famoso verso inicial do livro: "São Paulo! Comoção da minha vida". E há lugar, na cidade, para todas as contradições "arlequinais" de Mário de Andrade. Não há, paralelamente, como sair, como evadir-se de São Paulo:

Os vícios viciaram-me na bajulação sem sacrifícios...

Minha alma corcunda como a avenida São João...

E dizem que os polichinelos são alegres!

Eu nunca em guizos nos meus interiores arlequinais!...

\footnotetext{
${ }^{12}$ ANDRADE, 1993, p. 141.

13 ANDRADE, 1993, p. 85.
} 
Paulicéia, minha noiva... Há matrimônios assim...

Ninguém os assistirá nos jamais! ${ }^{14}$

Ei-los indissociavelmente juntos, mas perdidos um do outro: a euforia exterior do poeta e da cidade contrasta com o interior melancólico, avesso a efusões, de um lirismo que não podia entrar em descompasso com seu tempo, e que se exila no silêncio ou na alusão.

Na obra de Carlos Drummond de Andrade, a vida urbana corresponde a um tipo de experiência bem distinta. A cidade não é um campo de fusão temática e formal, como no autor de Paulicéia Desvairada, mas antes um ponto de bloqueio, um lugar de recusa e interdição.

Stop.

A vida parou

Ou foi o automóvel? ${ }^{15}$

Perdi o bonde e a esperança.

Volto pálido para casa.

A rua é inútil e nenhum auto

Passaria sobre o meu corpo. ${ }^{16}$

A dois passos da cidade importante

a cidadezinha está calada, entrevada. ${ }^{17}$

No Dummond dos primeiros livros, há um abismo (espacial e biográfico) entre o campo e a cidade:

Ah, ser filho de fazendeiro!

À beira do São Francisco, do Paraíba ou de qualquer córrego vagabundo,

é sempre a mesma sen-si-bi-li-da-de.

E a gente viajando na pátria sente saudades da pátria.

Aquela casa de nove andares comerciais

é muito interessante.

A casa colonial na fazenda também era...

\footnotetext{
${ }^{14}$ ANDRADE, 1993, p. 90.

${ }^{15}$ ANDRADE, 1973, p. 71.

${ }^{16}$ ANDRADE, 1973, p. 84.

17 "Sabará", de Alguma Poesia. In: ANDRADE, 1973, p. 57.
} 
No elevador penso na roça,

Na roça penso no elevador. ${ }^{18}$

Se há uma zona limítrofe, indecisa, ela é vista de passagem, votada à destruição e ao esquecimento:

Quando vou para Minas, gosto de ficar de pé, contra a vidraça do carro, vendo o subúrbio passar.

O subúrbio todo se condensa para ser visto depressa. com medo de não repararmos suficientemente em suas luzes que mal têm tempo de brilhar.

A noite come o subúrbio e logo o devolve, ele reage, luta, se esforça, até que vem o campo onde pela manhã repontam laranjais e à noite só existe a tristeza do Brasil. ${ }^{19}$

Nada mais oposto a estes versos de Drummond do que a poesia de Mário Quintana, onde as luzes do subúrbio como que brilham eternamente. Por vezes, a menção ao "último lampião de rua" é apenas isso, uma menção, capaz de por si mesma resumir toda a emoção poética do autor:

\section{BOCA DA NOITE}

O grilo canta escondido... e ninguém sabe de onde vem seu canto... nem de onde vem essa tristeza imensa daquele último lampião de rua... ${ }^{20}$

Na simplicidade extrema do poema em prosa de Sapato Florido, pode-se de qualquer modo notar uma leve ambigüidade: o primeiro pronome demonstrativo, referindo-se a "essa tristeza imensa", dá uma idéia de proximidade que justamente o pronome seguinte ("daquele") mergulha novamente na distância. Entre o próximo e o distante, há o som do grilo, que "ninguém sabe de onde vem". Sem usar de rimas, naturalmente, o texto ressoa de ecos em suas vogais repetidas de quando em quando: "ninguÉm/ vEm/nEm", como se fossem, ao mesmo tempo, os gritos do grilo repetidos na noite, e as lâmpadas enfileiradas, a intervalos, da iluminação

\footnotetext{
${ }^{18}$ ANDRADE, 1973, p. 77.

${ }^{19}$ ANDRADE, 1973, p 112.

${ }^{20}$ QUINTANA, 2005, p. 178.
} 
de rua. Estamos, de qualquer modo, a acompanhar as sensações de uma subjetividade estática, contemplativa, cujas interrogações e dúvidas se diluem em reticência, e que permite, em silêncio, ao ritmo do poema ser ocupado apenas pela pontuação sonora dos grilos, e visual, dos lampiões.

Numa das "Canções", livro publicado em 1946, o movimento é bem mais complexo.

\section{SEGUNDA CANÇÃO DE MUITO LONGE}

Havia um corredor que fazia cotovelo:

Um mistério encanando com outro mistério, no escuro...

Mas vamos fechar os olhos

E pensar numa outra cousa...

Vamos ouvir o ruído cantado, o ruído arrastado das correntezas no algibe, Puxando a água fresca e profunda.

Havia no arco do algibe trepadeiras trêmulas.

Nós nos debruçávamos à borda, gritando os nomes uns dos outros, E lá dentro as vozes ressoavam fortes, cavernosas como vozes de leões, Nós éramos quatro, uma prima, dois negrinhos e eu.

Havia os azulejos reluzentes, o muro do quintal, que limitava o mundo, Uma paineira enorme e, sempre e cada vez mais, os grilos e as estrelas. Havia todos os ruídos, todas as vozes daqueles tempos...

As lindas e absurdas cantigas, tia Tula ralhando os cachorros, O chiar das chaleiras...

Onde andará agora o pince-nez da tia Tula

Que ela não achava nunca?

A pobre não chegou a terminar a Toutinegra do Moinho, Que saía em folhetim no Correio do Povo!...

A última vez que a vi, ela ia dobrando aquele corredor escuro. Ia encolhida, pequenininha, humilde. Seus passos não faziam ruído. E ela nem se voltou para trás! ${ }^{121}$

A força deste poema, sem dúvida, está no enganoso contraste que propõem suas duas estrofes iniciais. Recusando-se a persistir na imagem sinistra do "corredor que fazia cotovelo", o poeta convida o leitor a "fechar os olhos/ e pensar noutra cousa..." Todavia, o que se segue não é uma paisagem solar e radiosa, mas outro espaço sombrio e enigmático; ao corredor escuro sucede-se um poço profundo, e o maior contraste entre

${ }^{21}$ QUINTANA, 2005, p. 158. 
os dois lugares está, apenas, na contraposição entre a dimensão horizontal, "que faz cotovelo", e a vertical, do algibe. Este possui, entretanto, uma virtualidade acústica que o corredor não apresenta; na beira do poço, "havia todos os ruídos, todas as vozes daqueles tempos", enquanto a tia Tula some pelo corredor, e "seus passos não faziam ruído". No plano horizontal, a sucessão do tempo terá forçosamente de ser interrompida, como a leitura dos folhetins publicados no Correio do Povo. Já o plano vertical, feito de interioridade e de memória, pode guardar e mesmo amplificar - os sons de outro tempo, que se puxam, se arrastam e seguem o andar das trepadeiras, vencendo, como a água que se retira com esforço do poço, a escuridão.

Esse jogo entre o horizontal e o vertical, entre o desaparecimento e a memória, não seria também o jogo entre a prosa e o verso, entre as sonoridades recolhidas no poema e a fala passageira do jornal? "Non, je ne veux ni prose, ni vers", declarava famosamente o M. Jourdain de Molière, lembrado na epígrafe de Sapato Florido. A vasta e constante produção de circunstância de Mario Quintana, em especial a de seu Caderno H, por muitos anos publicada no Correio do Povo, surge assim quase como resultado de um "parti-pris" programático. Esquecimento e memória, corredor e poço, tudo o que é passagem e horizontalidade, assim como tudo o que é permanência e profundidade, pertencem a um mesmo "sistema", onde, para lembrar o verso do autor, há "um mistério encanando com outro mistério".

Tia Tula reaparece no "Caderno H", assim como o lampião de rua:

\section{O VIAJANTE ÀS AVESSAS}

...até que o condutor me bateu no ombro. "Fim da linha, seu moço."

Desci. E fui andando, meio desconfiado.

Praças com bancos de madeira, curvos e verdes como as árvores. O pé-de-moleque do calçamento irregular da rua. Os lampiões de esquina.

O quiosque (um quiosque!) de revistas, cigarros, balas, miudezas.

Mas fui andando, andando - como é que eu sabia o caminho? -e finalmente entrei na velha copa de azulejos, lá onde Tia Tula já estava, como sempre, servindo o gostoso café com leite. Entreparou e disse: - Mas por onde terá andado esse menino?!

Aquele seu jeito, tão dela, de ralhar na terceira pessoa...

E, como eu ainda estivesse com um ar ausente: "Meu Deus, em que será que esse menino pensa tanto?" E acrescentou, baixinho:

- Até parece um velho de sessenta anos! 
A surpresa, um tanto fácil, da frase final não diminui a arte quase imperceptível com que surge a verdadeira surpresa desse poema em prosa: a aparição, ou melhor, a transformação da rua em copa de azulejos, sem que o poeta explique de que modo a casa antiga se encontrava no meio daquela rua no fim da linha. É que a rua desconhecida, onde a cidade termina, permite justamente o reencontro com o familiar; do mesmo modo, tia Tula se dirige com intimidade ao menino Quintana, mas o faz na terceira pessoa. De certa forma, o fim da cidade é o começo do mundo, ou pelo menos é assim na memória de infância do poeta, como se uma indefinida expansão urbana distanciasse, mais e mais, o autor de seu passado.

Para Mario Quintana, a poesia - ou o que há de imediatamente "poético" num lampião de rua ou no canto esparso dos grilos, por exemplo - estaria assim numa espécie de colisão, de encontro súbito entre dois tempos: o tempo sucessivo, marcado pelo envelhecimento, pelo prolongar-se horizontal dos postes de luz pelo caminho, pela seqüência dos dias e dos anos, e um outro tempo, o que se guarda na memória, nos baús, nas caixas de charuto vazias, nos cofres de miudezas, na concha mágica dos bares e das copas de casa antiga. Não se trata de uma poesia que invoque, como a de Drummond, uma "suspensão do tempo", obtida por meio de laborioso sortilégio discursivo, ou que promova, como a de Manuel Bandeira, o encantamento da repetição cotidiana.

Sem dúvida mais tradicional nesse ponto, a poesia de Mário Quintana precisa do acidente para acontecer; daí o seu senso de surpresa, sua dependência da "trouvaille", sua condição tendente ao aforismo. O aforismo, justamente, é o curto-circuito de um raciocínio, e se formalmente se assemelha, quando melodioso, ao verso, não deixa de ser, intelectualmente, uma concentração da prosa; é prosa iluminada, mas modesta, como um lampião de rua que subitamente é acendido. O aforismo só funciona plenamente quando irrompe em paradoxo, e um paradoxo, se podemos formular assim, é como uma esquina imprevista do pensamento...

A experiência da vida urbana como um bloqueio, que notávamos na poesia de Drummond, costuma ser também ocasião para a transcendência, ao menos na evolução incomparável do poeta mineiro, que parte do prosaico em direção ao metafísico. Do célebre "meio do caminho", onde "tinha uma pedra/ tinha uma pedra no meio do caminho" - obstáculo aparentemente intransponível para as "retinas tão fatigadas" do jovem poeta de 1930 -, passamos a "uma estrada de Minas, pedregosa", onde se entreabre "A Máquina do Mundo", na maturidade do autor. 
A poesia de Drummond não desconhece a "curva desta escada", assim como a de Quintana encontra fascínio "na volta da escada,/na volta escura da escada". Comparem-se, entretanto, os poemas de um e outro. Quintana fala de um "Anjo da Escada":

Na volta da escada,

Na volta escura da escada,

O Anjo disse o meu nome.

E o meu nome varou de lado a lado meu peito.

E vinha um rumor distante de vozes clamando clamando...

Deixa-me!

Que tenho eu a ver com tuas naus perdidas?

Deixa-me sozinho com os meus pássaros...

com os meus caminhos...

com as minhas nuvens...

Os versos finais, como é evidente, se organizam como degraus de uma escada, e semanticamente apontam para o alto e para longe (nuvens /caminhos/ pássaros), recusando entretanto a transcendência proposta pelo anjo, capaz de varar seu peito numa agressão em ângulo reto e mortífero. O anjo propõe ao poeta um reencontro com seu nome próprio; mas, se entendemos bem o sentido dos últimos versos, o poeta se recusa ao gesto do anjo, reivindicando para si mesmo o dom de voar com seus próprios pássaros, com suas próprias nuvens; o "angelismo" de Mário Quintana constitui, sem dúvida, uma de suas marcas registradas e uma das chaves de seu sucesso popular.

O universo do pecado, sem dúvida ausente em Mário Quintana, ${ }^{22}$ vibra como nunca no poema de Drummond:

\footnotetext{
${ }^{22}$ Uma exceção que confirma a regra seriam estes versos de seu "Poema para Juliano, o Apóstata”: “... veio um deus usurpador e único/e tornou o mundo incompreensível/porque o seu reino não era deste mundo.//E até hoje ninguém soube por que então ele expulsou os outros deuses/e ficou reinando sozinho/e fez todos os homens pecarem/ - coisa que eles jamais haviam feito antes -/ porque pecar com inocência não é pecar...//E os homens conheceram o terror maravilhoso do pecado/ -e assim o novo deus thes trouxe uma volúpia nova." QUINTANA, 2005, p. 413-414.
} 


\section{ESCADA}

Na curva desta escada nos amamos, Na curva desta escada nos perdemos.

O caprichoso esquema unia formas vivas, entre ramas. Lembras-te, carne? Um arrepio telepático vibrou nos bens municipais, e dando volta ao melhor de nós mesmos, deixou-nos sós, a esmo, espetacularmente sós e desarmados, que a nos amarmos tanto eis-nos morridos.

Aqui se esgota o orvalho, e de lembrar não há lembrança. Entrelaçados, insistíamos em ser; mas nosso espectro, submarino, à flor do tempo ia apontando, e já noturnos, rotos, desossados,

nosso abraço doía para além da matéria esparsa em números. ${ }^{23}$

Estamos longe, por certo, da acolhedora copa azulejada que se encontra no final de uma rua desconhecida... É que a esquina, o fim da rua, e mesmo a volta do corredor escuro, são para Quintana um lugar de mistério, de imprevisto, e portanto de salvação. Que o poeta recuse os apelos do anjo, numa volta da escada, não diminui sua confiança em si mesmo, em sua própria capacidade de ascender às nuvens; afinal, ele é "poeta", numa acepção bem pouco moderna do termo, enquanto Drummond, cujo ritmo e desespero são bem os de um salmista sem Deus, perde-se em outras profundezas e altitudes.

Talvez nessa comparação se possa ver o encanto, e os limites, de Mário Quintana; há algo de irreparavelmente "não-moderno" na confiança que ele tem ao ser "poeta", figura esquisita e inofensiva a circular entre seus concidadãos. Natural, de qualquer modo, que procure o fim da linha dos bondes, os arrabaldes da cidade: reencontra o ambiente doméstico da infância, avesso ao progresso urbano, onde ainda as velhas tias o recebem, com um misto de carinho e estranhamento.

${ }^{23}$ ANDRADE, 1973, p. 285-286. 
4

A expansão urbana, ao que há de irreconhecível na cidade moderna, aparece mais tarde na obra de Quintana. Em "Apontamentos de História Sobrenatural", publicado em 1976, podemos ler "SOS em Babilônia":

Na cidade dos ruídos mecânicos, atrozes

- Onde as rãs, onde os grilos, onde as misteriosas vozes

que urdiam a rede dos côncavos silêncios noturnos?

Os arroios se foram no ralo agonizante das pias...

As últimas procissões

com as suas campânulas cada vez mais remotas

vão andando de costas como um filme passado às avessas...

(Eu estou gravando esse lento poema nas paredes de uma cela)

De novo, é aquele espaço estreito e vertical, dos porões e dos algibes, que garante a sobrevivência do poeta; só que, anteriormente, seguir "horizontalmente" uma rua até o fim era o procedimento mágico por meio do qual, ao encontrar o último poste, se podia também reencontrar o passado; qualquer caminhada até os arrabaldes da cidade significava uma volta no tempo, uma "procissão às avessas"; o ar da noite, com seus grilos, significava um "fim de linha" que era ao mesmo tempo uma parada no progresso. Agora, "os arroios se foram no ralo agonizante das pias", e o movimento em direção às profundezas da memória não tem mais equivalente na paisagem urbana. O poeta se vê preso em seu quarto de hotel, e com isso sua poesia ganha uma dramaticidade, uma angústia bem maiores. Para bem ou para mal, entretanto, Quintana evita ainda a sufocação drummondiana, confiando na função tradicional de "vate" para salvar-se do mundo modernamente agressivo que o cerca.

\section{LUNAR}

As casas cerraram seus milhares de pálpebras.

As ruas pouco a pouco deixaram de andar.

Só a lua multiplicou-se em todos os poços e poças.

Tudo está sob a encantação lunar... 
E que importa se nossos artefatos

lá conseguiram afinal chegar?

Fiquem armando seus sábios bodoques:

a própria lua tem sua usina de luar...

E mesmo o cão que está ladrando agora

é mais humano que todas as máquinas.

Sinto-me artificial com esta esferográfica.

Não tanto... alguém me há de ler com um meio sorriso

Cúmplice... Deixo pena e papel... E, num feitiço antigo,

à luz da lua inteiramente me luarizo.... ${ }^{24}$

A mesma "colisão temporal" que identificávamos na narrativa de "O Viajante às Avessas" reaparece aqui, sem alteração quanto à atitude subjetiva do poeta, mas como uma mudança notável no aspecto formal: é a própria linguagem do poema que se impregna de duplicidade, que procura reunir, em seu vocabulário e em suas metáforas, um passado eterno e o senso linear da sucessão histórica. Assim, a "esferográfica" com que os versos estão sendo escritos se transmuta em "pena" dois versos adiante. Trata-se todavia de sinônimos exatos: se o poeta se sente "artificial" usando a esferográfica, não é que a abandone em favor de uma pena de ganso passadista, prestigiosa e lírica: o utensílio que deixa de usar é simplesmente chamado de "pena" logo depois, mas o termo continua designando a mesma esferográfica de antes... A mesma ambigüidade pode ser percebida quando, em vez de "foguetes", Quintana usa "bodoques" para falar dos utensílios tecnológicos que levam o homem até a Lua. Em princípio, "bodoques" teria a ressonância simpática de um brinquedo antigo da infância; é utilizado pejorativamente, entretanto, para desqualificar a tecnologia contemporânea. Um poeta antipático à tecnologia e afetuoso com relação ao passado deveria, a rigor, evitar a metáfora, que se orienta numa direção inversa à do sentido subjetivo do poema. Ademais, o cuidado em não parecer piegas e ultrapassado se revela num sutil toque modernizante de vocabulário: seria impublicável, em 1976, um verso que dissesse "Tudo está sob o encanto do luar"; embora fosse este, com certeza, o significado fundamental das palavras do poeta, o verso evita o anacronismo, preferindo: "Tudo está sob a encantação do luar". O

${ }^{24}$ QUINTANA, 2005, p. 394-395. 
recurso levemente marioandradiano ao neologismo repete-se no "luarizo" final: a modernidade, enfim, aparece como solução formal, talvez um tanto maneirista, para diminuir o efeito "romântico" da conhecida contraposição entre "a lua dos poetas" e a "dos astronautas".

Formas semelhantes de ambigüidade podem ser encontradas em outro poema desse período, em que a violência da arquitetura moderna sobre a antiga paisagem urbana é denunciada, mas num meio-sorriso, sem os gélidos frenesis baudelairianos. Em "Poema de Circunstância", com efeito, a experiência avassaladora da modernidade assume um tom de cantiga de roda:

Onde estão os meus verdes?

Os meus azuis?

O Arranha-Céu comeu!

E ainda falam nos mastodontes, nos brontossauros, nos tiranossauros, Que-mais sei eu...

Os verdadeiros monstros, os Papões, são eles, os arranha-céus! $!^{25}$

A habilidade de Mário Quintana em evitar o lugar-comum romântico, sem deixar de reiterá-lo, responde à expectativa generalizada de encontrar, na figura do poeta, uma alma que não ignora as violências da modernidade, mas que ao mesmo tempo sabe preservar as artes da sensibilidade e a delicadeza da infância. Modéstia extrema, discrição e humor são necessários a Mário Quintana para prosseguir nesse objetivo, nesse constante esforço de auto-limitação.

Seu "caso literário" seria entretanto simples se o resumíssemos assim. É que, apesar dos luares e do tom indubitavelmente mavioso de muitos de seus poemas, o imaginário de Quintana se abre para outro tipo de experiência psicológica, a do horror. Não se trata apenas do "mistério poético" que tantas vezes seus versos evocam nos corredores e porões. Sem dúvida, há nostalgia convencional nesta elegia às casas de antigamente:

${ }^{25}$ QUINTANA, 2005, p. 442. 


\section{ARQUITETURA FUNCIONAL}

Não gosto da arquitetura nova

Porque a arquitetura nova não faz casas velhas

Não gosto das casas novas

Porque as casas novas não têm fantasmas

E, quando digo fantasmas, não quero dizer essas assombrações vulgares

Que andam por aí...

É não-sei-quê de mais sutil

Nessas velhas, velhas casas,

Como, em nós, a presença invisível da alma...

(...) E as casas novas não têm ao menos aqueles longos, intermináveis corredores

Que a Lua vinha às vezes assombrar! ${ }^{26}$

Ainda que rememorado de forma humorística, tem outro potencial de inquietação o "Conto Azul" do Caderno $H$ :

Certa vez, tinha eu quinze anos, inventei uma história que principiava assim:

"A primeira coisa que fazem os defuntos, depois de enterrados, é abrirem novamente os olbos"27

E a lua capaz de ainda encantar o poeta de Apontamentos de História Sobrenatural não é a mesma que surgia, anos antes, em Sapato Florido:

Tão de súbito, por sobre o perfil noturno da casaria, tão de súbito surgiu, como um choque, um impacto, um milagre, que o coração, aterrado, nem lhe sabia o nome - a lua!- a lua ensangüentada e irreconhecível de Babilônia e Cartago, dos campos malditos de apósbatalha, a lua dos parricídios, das populações em retirada, dos estupros, dos primeiros e últimos tempos. ${ }^{28}$

Uma forma talvez mais sutil de horror se vislumbra numa interrogação curta do Caderno $H$ :

O relógio de parede numa velha fotografia - está parado?29

\footnotetext{
${ }^{26}$ QUINTANA, 2005, p. 397-398.

${ }^{27}$ QUINTANA, 2005, p. 278.

${ }^{28}$ QUINTANA, 2005, p. 173.

${ }^{29}$ QUINTANA, 2005, p. 237.
} 
Não é casual que, nestes três exemplos da poesia menos "doce" de Quintana, encontre-se o mesmo fenômeno da colisão temporal descrito acima. O morto que abre os olhos, a lua "dos primeiros e últimos tempos", o relógio que está parado e no entanto funciona, tornam simultâneos o presente e o passado, mas essa simultaneidade não se resolve em conciliação e reencontro; é motivo de estranheza e medo. Trata-se, sem dúvida, do Quintana mais "moderno", ao refletir um desajuste entre o presente, em que cumpre viver, e o passado, origem de todo impulso lírico.

O sentido eufórico do futuro, que tanto prejudicou a primeira poesia modernista, oscilante entre utopia e derrisão do progresso, é assim vencido sutilmente nos melhores momentos de um poeta anacronicamente "poetizante" como Mario Quintana. O horror das cidades "tentaculares" de Verhaeren desaparece nas paisagens suburbanas de província; mas renasce na contemplação de um passado que não quer morrer. Há, em toda a obra de Quintana, a tentação de ressuscitá-lo magicamente, "poeticamente", num ato de ternura; melhor quando o poeta se mostra consciente de que esse passado, que julgávamos morto pelos artefatos do progresso, é capaz de manter-se horrivelmente de olhos abertos, como um vampiro. Numa dobra de esquina, no fim de um corredor escuro, o desconhecido não é apenas abertura para o encantamento, como percebe o "Terceiro Poema de Muito Longe":

Da última vez que atravessei aquele corredor escuro, Ele estava cheio de passarinhos mortos. ${ }^{30}$

Esses passarinhos eram, talvez, muitos dos seus próprios poemas; ou, ao menos, a concepção de uma poesia canora, para a qual Mario Quintana estava sem dúvida vocacionado desde seus primeiros sonetos, e que sua situação histórica, marcada pela herança modernista, obrigou a "prosificar". Avesso, entretanto, à "tradição de ruptura" característica das distintas fases da vanguarda artística no século 20, a experiência do horror em Quintana desvinculou-se da intenção, tipicamente urbana, do "choque". ${ }^{31}$ Longe das agressões de uma "paulicéia desvairada", e próximo de uma experiência de cidades acolhedoras, onde a fronteira descampada da noite ainda é sinal de uma natureza ameaçadora e estrangeira, o poder

\footnotetext{
${ }^{30}$ QUINTANA, 2005, p. 459.

${ }^{31}$ Cf. a esse respeito o ensaio de BENJAMIN, 1989, p. 103-149.
} 
poético do "choque" traduziu-se, principalmente, num poder de iluminação feliz. Daí o gosto do autor pelo aforismo. E pelos últimos lampiões de rua também.

\section{Referências Bibliográficas}

ANDRADE, Carlos Drummond de. Poesia Completa e Prosa. Rio de Janeiro: Aguilar, 1973.

ANDRADE, Mário de. Poesias Completas. Edição crítica de Diléa Zanotto Manfio. Belo Horizonte/Rio de Janeiro: Villa Rica, 1993.

BACHELARD, Gaston. Poética do Espaço. São Paulo: Abril Cultural, 1978. (Col. Os Pensadores)

BENJAMIN, Walter. Sobre alguns temas em Baudelaire. In: Charles Baudelaire Um lírico no auge do capitalismo. São Paulo: Brasiliense, 1989.

QUINTANA, Mário. Poesia Completa. Rio de Janeiro: Nova Aguilar, 2005.

VERHAEREN, Émile. Cidades Tentaculares. Edição bilíngue, com tradução e apresentação de José Jerônimo Riveyra. Brasília: Thesaurus, 1999.

\section{Resumo}

Em contraste com a poesia de Mario de Andrade e Carlos Drummond de Andrade, a experiência da vida urbana na obra de Mário Quintana é menos um motivo de euforia e desalento que de ambigüidade: neste artigo, relaciona-se essa ambigüidade com o caráter ambíguo da própria poesia de Quintana, entre o erudito e o popular, o moderno e o convencional, a prosa e o verso.

\section{Abstract}

The experience of urban life assumes, in Mário Quintana' poetry, a different character in comparison to the works of other brazilian modernist poets, such as Mario de Andrade and Carlos Drummond de Andrade. Not an expression of enthusiasm or hindrance, Quintana's verses reveal an ambiguity that can be related to the author's own oscillation between prose and poetry, modernism and conventionalism, sophistication and directness. 